\title{
Sanctions for research misconduct in cardiothoracic surgery journals
}

\author{
Robert M. Sade, MD, for the Cardiothoracic Ethics Forum
}

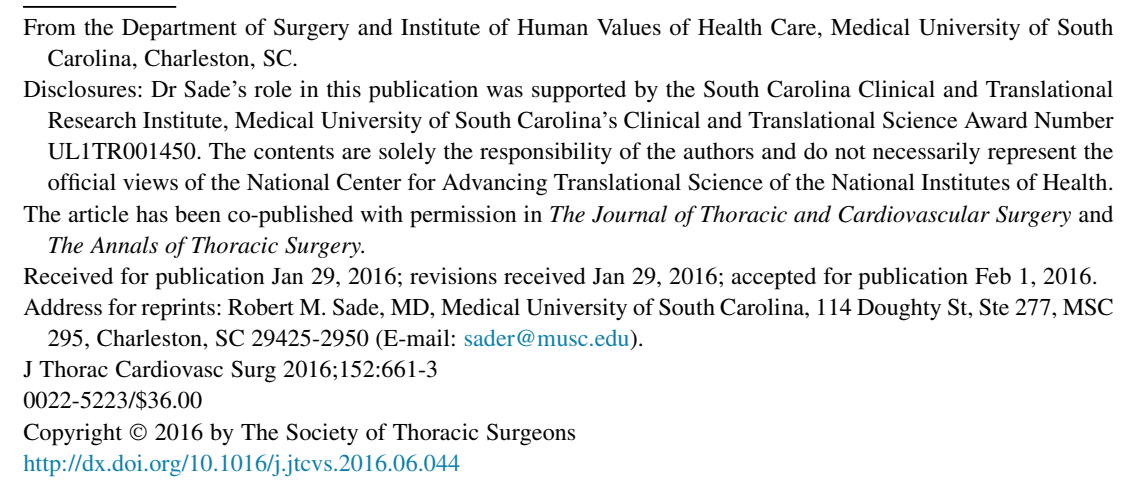

Research misconduct-namely, redundant publication, falsification and fabrication of data, and plagiarism, among others-has grown consistently in biomedical and scientific research over the last few decades. The leading motivation for misconduct is intense competition for promotion and tenure and for funding of grants. Competition in general has many positive effects, such as encouraging productiveness and innovation. Excessive competition, such as exists in biomedical research, however, can be harmful in many ways, ranging from subtle transgressions such as overemphasizing positive results while minimizing limitations, to severe misconduct such as outright fraud. ${ }^{1}$ Several studies in recent years have documented the trend of increasing violations of research ethics.

In 2012, PubMed found 2047 retractions among biomedical and life science research articles, dating back to $1973 .{ }^{2}$ More than two thirds of those articles were retracted because of research misconduct, most commonly fraud or suspected fraud and duplicate publication. The rise in retraction of published papers over time is documented in Figure 1. All causes of retraction have increased markedly from the 1970s, but especially during the period 2007 to 2011 (Figure 1, A). The phenomenon is worldwide. The increase in retractions cannot be attributed to the increased volume of publication, because the rate of retraction (incidence of fraud or suspected fraud as a percentage of total articles) has increased tenfold since 1975 (Figure 1, B). ${ }^{2}$

A survey of several thousand early and mid career scientists asked about their personal involvement in any of 16 unethical practices, which ranged from fabricating and falsifying research data to keeping inadequate records. ${ }^{3}$ The top 10 of the practices were considered to be the most serious, and the investigators found, "overall, thirtythree percent of the respondents said they had engaged in at least one of the top ten behaviors during the previous three years," a staggering finding. These were self-

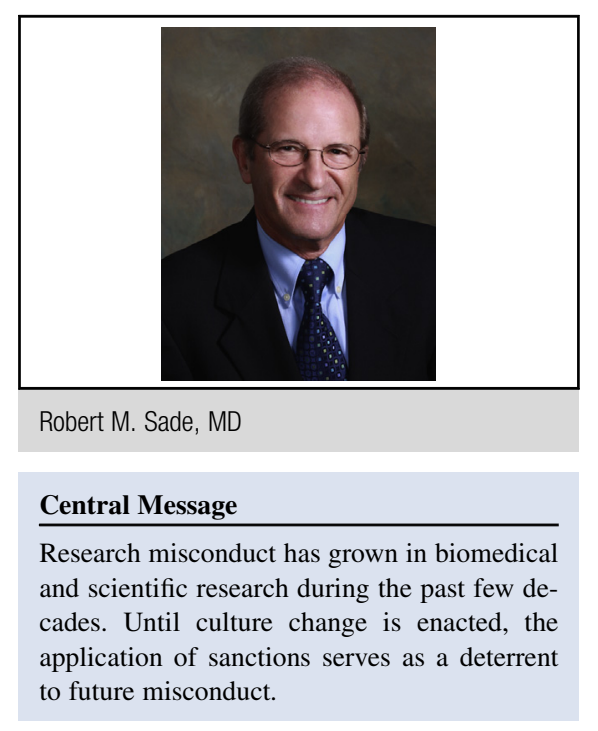

reports, so it seems likely that research misconduct was underreported in the survey. Unethical conduct in research undermines the foundations of science which, by its nature, is built upon prior evidence, and when that evidence is false, the foundations are weakened. Perhaps the worst implication of misconduct is that it poses significant risks to patients. $^{4}$

By engaging in research misconduct, investigators hurt themselves as well as the scientific enterprise. A search of the Office of Research Integrity records identified 47 senior authors who were found to have engaged in research misconduct. From 6 years before the finding of misconduct to 6 years after the finding, these authors' publications decreased by an average of $74.6 \%$, a median of $91.8 \%$. A majority of the investigators dropped to 0 publications, suggesting that at least some of them lost their positions. The investigators also sustained major declines in funding. ${ }^{5}$ In cases of fraud, there may also be unfortunate collateral damage to others associated with the offenders, coinvestigators who themselves are not guilty of fraud. Despite the documented risks of self-inflicted damage, research misconduct continues to increase.

Many ideas for improving the culture of science have been proposed, including reforming the structure of the scientific enterprise ${ }^{6}$ and improving the reliability of research publications. ${ }^{7}$ The suggested reforms are mostly long term, and they face resistance from established institutions. An 

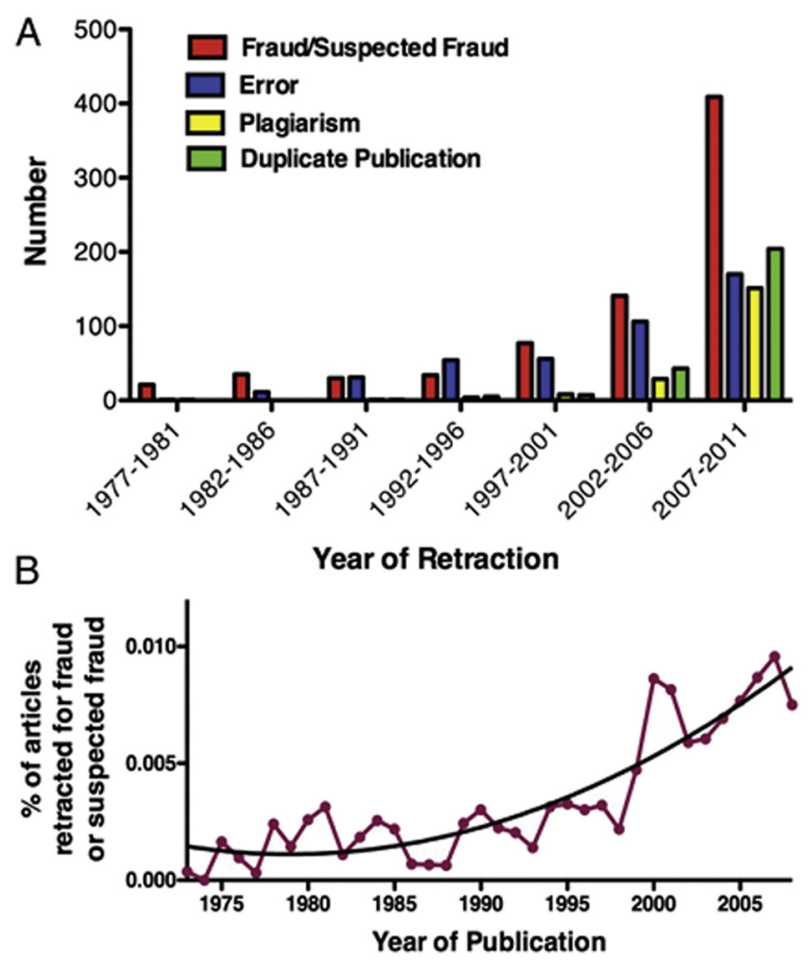

FIGURE 1. A, Number of retracted articles for specific causes by year of retraction. B, Percentage of published articles retracted for fraud or suspected fraud by year of publication. The solid line is the line of best fit. (By permission of the Proceedings of the National Academy of Sciences. ${ }^{2}$ )

immediate corrective action when misconduct is found, however, is application of sanctions, which may serve as deterrents to future violations.

\section{VIOLATION OF PUBLICATION STANDARDS IN CARDIOTHORACIC SURGERY JOURNALS}

Redundant publication is a common form of publication misconduct in the cardiothoracic surgery literature. A joint statement on this transgression was published in 6 journals over the signatures of their respective editors in September $2015 .{ }^{8}$ Redundant publication was defined as a publication that overlaps substantially with a paper submitted or published elsewhere without adequate cross-referencing and justification. Adoption of this joint statement was considered to be an important step in combating this practice.

The joint statement listed 5 criteria that had to be satisfied to determine redundancy: (1) the numbers and sample sizes are similar; (2) the methodology is identical or nearly so; (3) the results are similar; (4) at least 1 author's name is common to both reports; and (5) little or no new information is made available.

The editors consider redundant publication to be serious academic misbehavior, and stated that such violations could be reported to specialty society ethics committees for possible disciplinary action.
Missing from the statement are details of sanctions that journals may apply in such cases, beyond reporting to ethics committees. To fill that gap, The Annals of Thoracic Surgery and The Journal of Thoracic and Cardiovascular Surgery have developed a policy describing actions that journals may take in cases of redundant publication and other forms of research publication misconduct.

\section{RECOMMENDATIONS \\ Redundant (Duplicate) Publication}

Redundant (duplicate) publication occurs along a spectrum of misconduct. Clearcut redundant publication occurs when there is no reasonable doubt that an identical or nearly identical paper was submitted to or published in 2 or more different journals. Presumptive redundant publication occurs when the preponderance of evidence points to misconduct in the submission or publication of substantially similar papers to 2 or more different journals. ${ }^{8}$

When possible redundant publication is suspected, the corresponding or senior author will be contacted to explain the apparent redundancy. Based on the evidence of the papers and the explanation, a committee of the editorial board chaired by the editor and dedicated to review of violations of publication standards will determine whether clearcut or presumptive redundant publication has in fact occurred.

Cases of clearcut redundant publication will be shared with the editors of other major cardiothoracic surgery journals. ${ }^{1}$ The journal will ban publication of papers submitted by all authors listed on the offending papers for 2 years, and the matter will be referred to the parent organization's respective ethics committee for possible further disciplinary action against authors who are members of the parent organization. The authors' home institutions will also be notified of the finding of duplicate publication.

In cases of presumptive redundant publication, the editor has the option to write a letter of reprimand to the author or authors of the offending papers or impose a publication ban on the authors for 1 or 2 years. The editor may also notify the home institution and the editors of other major cardiothoracic surgery journals. ${ }^{1}$

\section{Research Misconduct}

Research misconduct is defined in federal policy as falsification or fabrication of data or plagiarism. ${ }^{9}$ When misconduct in a research report is suspected, the corresponding or senior author will be contacted to explain the apparent transgression. Based on the evidence of misconduct and the author's explanation, a committee of the editorial board chaired by the editor and dedicated to review of violations of publication standards will determine whether misconduct has probably occurred. When the preponderance of evidence suggests misconduct, the matter will be referred to the institution in which the research was carried out or the 
institution of which the author is a member for further investigation.

When an institution informs the journal that its investigation has concluded that research misconduct has occurred in a report submitted or a paper published in the journal and names the person or persons responsible for the misconduct, the journal will accept this conclusion as fact. The journal will ban publication of papers submitted by the responsible person or persons for 2 years or more, up to permanent ban, depending on the severity of the transgression. In addition, the matter will be referred to the parent organization's ethics committee for possible further disciplinary action against authors who are members of the organization. Offending articles that have been published will be retracted.

Cardiothoracic Ethics Forum Members: Charles Canver, MD, Thomas D'Amico, MD, Jennifer Ellis, MD, Kathleen Fenton, MD, Richard Freeman, MD, David Fullerton, MD, Lynn Harrison, MD, James Jaggers, MD, James Jones, MD, Leslie Kohman, MD, John Mayer, MD, Martin McKneally, MD, Walter Merrill, MD, Scott Millikan, MD, John Mitchell, MD, Scott Mitchell, MD,
Susan Moffatt-Bruce, MD, Robert Sade, MD, Mark Slaughter, MD, Sandra Starnes, MD, Gregory Trachiotis, MD, Richard Whyte, MD, and Douglas Wood, MD.

\section{References}

1. Casadevall A, Fang FC. Reforming science: methodological and cultural reforms. Infect Immun. 2012;80:891-6.

2. Fang FC, Steen RG, Casadevall A. Misconduct accounts for the majority of retracted scientific publications. Proc Nat Acad Sci USA. 2012;109:17028-33.

3. Martinson BC, Anderson MS, de Vries R. Scientists behaving badly. Nature. 2005 435:737-8.

4. Steen RG. Retractions in the medical literature: how many patients are put at risk by flawed research? J Med Ethics. 2011;37:688-92.

5. Stern AM, Casadevall A, Steen RG, Fang FC. Financial costs and personal consequences of research misconduct resulting in retracted publications. eLife. 2014;3: e02956.

6. Fang FC, Casadevall A. Reforming science: structural reforms. Infect Immun. 2012;80:897-901.

7. Ioannidis JP. How to make more published research true. PLoS Med. 2014;11: e1001747.

8. Kumar AS, Beyersdorf F, Lazar HL, Denniss AR, Patterson GA, Weisel RD. Joint statement on redundant (duplicate) publication by the editors of the undersigned cardiothoracic journals. Ann Thorac Surg. 2015;100:784.

9. Office of Research Integrity. Definition of research misconduct. Available at: http://ori.hhs.gov/definition-misconduct. Accessed January 20, 2016. 